This item was submitted to Loughborough's Research Repository by the author.

Items in Figshare are protected by copyright, with all rights reserved, unless otherwise indicated.

\title{
Professor Jim James ... a great researcher and motivator in the field of antennas
}

PLEASE CITE THE PUBLISHED VERSION

LICENCE

CC BY-NC-ND 4.0

\section{REPOSITORY RECORD}

Whittow, W.G., Maria I. Kitra, J.C. Vardaxoglou, C.J. Panagamuwa, Patrick McEvoy, and J.R. James. 2019. "Professor Jim James ... A Great Researcher and Motivator in the Field of Antennas". figshare. https://hdl.handle.net/2134/3058. 
This item was submitted to Loughborough's Institutional Repository by the author and is made available under the following Creative Commons Licence conditions.

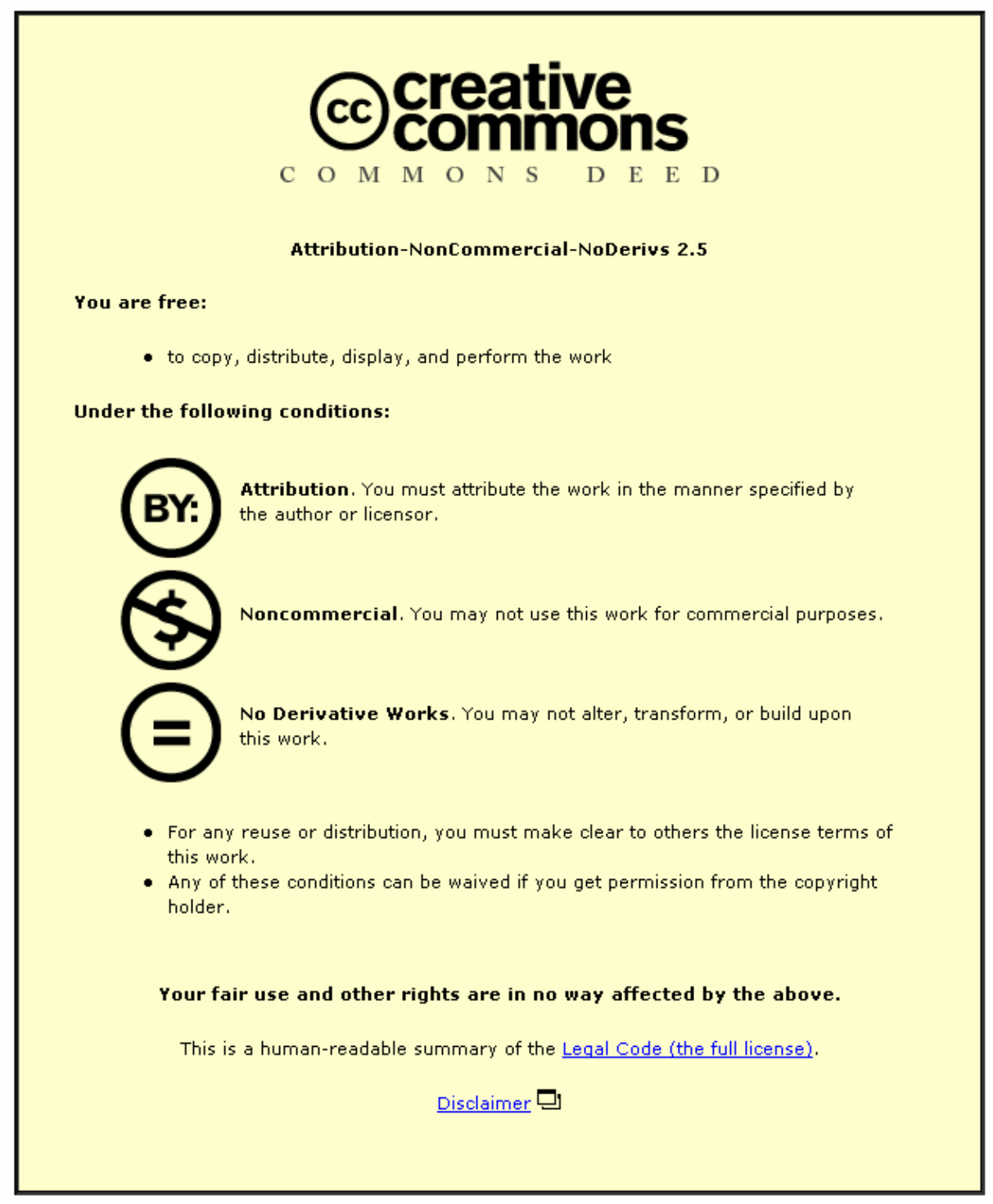

For the full text of this licence, please go to: http://creativecommons.org/licenses/by-nc-nd/2.5/ 


\title{
PROFESSOR JIM JAMES...A GREAT RESEARCHER AND MOTIVATOR IN THE FIELD OF ANTENNAS
}

\author{
W. G. Whittow ${ }^{\dagger}$, M. I. Kitra, J. C. Vardaxoglou ${ }^{\dagger}$, C. J. Panagamuwa ${ }^{\dagger}$, P. McEvoy, J. R. James \\ ${ }^{\dagger}$ Loughborough University, Leicestershire, LE11 3TU. UK, \\ w.g.whittow@lboro.ac.uk,j.c.vardaxoglou@lboro.ac.uk,c.j.panagamuwa@lboro.ac.uk
}

Keywords: J. R. James, small antennas, low SAR antennas

\begin{abstract}
This paper is dedicated to Professor Jim James. It is a celebration of his life, career and world renowned research contribution to the engineering community. Jim was eminent for his pioneering research contributions to the fundamental understanding of radiation mechanisms in printed patch and small antennas including seminal achievements, both theoretical and in terms of demonstrated practical applications, in communications, radar and medical electronics. The paper includes a brief summary of his research. Details will also be included on some of his latest work involving low SAR material coated mobile handset antennas.
\end{abstract}

\section{Introduction}

Professor J. R. James - mathematician, engineer, teacher and an outstanding researcher in the field of high frequency electromagnetic radiation problems, died peacefully on Monday 24 July 2006 after a struggle with cancer, at age 73.

Professor Jim James was born in 1933 on the Isle of White, in the UK and was educated at London University obtaining the degrees; BSc (Special Maths 1965), PhD (1968) and the DSc (1980). As well as serving his national service and a period of industrial work on radar at E. K. Cole of Malmsbury, Wiltshire, Jim worked as an analytical chemist, a physicist on a neutron project at the Harwell nuclear accelerator and as a transistor application designer. In 1967, Jim joined academia at the Royal Military College of Science (RMCS) at Cranfield University. He was made a Special Merit Professor (1976-84) and then Professor of Electromagnetic Systems (1984-98) and was Head of the School of Electrical and Electronic Engineering. He created and directed the Wolfson RF Engineering Centre specialising in both defence-oriented and industrial research on printed antenna technology, size reduced antennas, millimetric radiators for guided weapons, stealth radar coatings and waves in composite materials, speech processing, electromagnetic heating in medical engineering and optical systems. His contributions were recognised by two Individual Special Merit Award promotions. This research led to numerous patents and some 200 refereed publications despite much of his work being classified. These papers received 9 IEE awards. Jim also supervised 25 successful doctoral students.

He was the Editor of Research Studies Press (RSP) International Research Monographs on antennas and electromagnetics and has also contributed seven major books with international experts including the classic texts on the subject of microstrip antennas and arrays; Microstrip Antenna Theory and Design (1983) and the Handbook of Microstrip Antennas (1989) and the IEE Peter Peregrinus series. Professor James has served on numerous technical committees for conferences and institutions and was a Past President of the Institute of Electrical and Radio Engineers IERE (1984-85) and Chairman of the Institute of Electrical Engineers (IEE) Electronics Division (1988-89). He also chaired the IERE Papers Committee (1970-75) and the IEE E11 Antennas/Propagation Committee (1980-83). He was elected a Fellow of the Royal Academy of Engineering in 1987 and inducted to the Electromagnetics Academy in 1990. He was elected a Fellow of the IEE and also of the Institution of Mathematics and its Applications. He has been a Visiting Professor in Malaysia (1994) and Hong Kong (1999). Since 1998 he an Emeritus Professor of Cranfield University and a Visiting Professor at Loughborough University. Jim also worked as a consultant to many industrial, academic and governmental organisations.

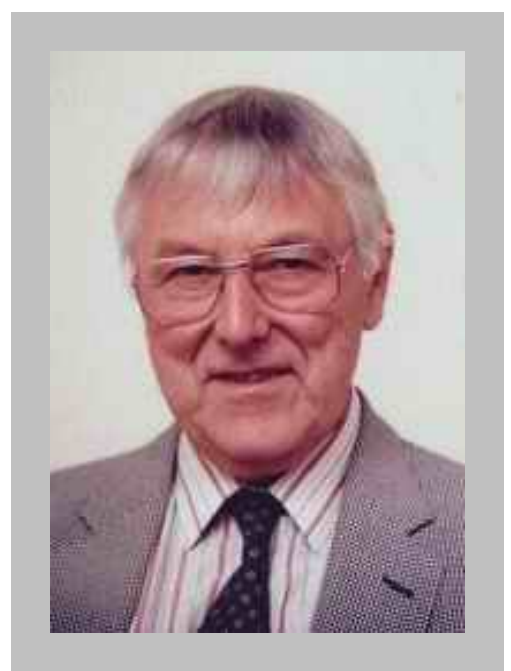

Figure 1. Professor Jim James. 
Amazingly, despite his illness, Jim continued his research activity and collaborations, still publishing papers right up until a few weeks before his death. Jim was a highly valued colleague and a personality of great calibre who will be greatly missed by all of us at both Cranfield and Loughborough Universities and leaves a big hole in the life of these Schools. Jim is survived by his wife Pam; his son and daughter, Julian and April and by four grandchildren, Thomas, Alice, Runar and Magnus.

\section{Research}

Jim's innovative contributions to science arose from his ability to address both the fundamental complex theory of electromagnetics and the practical realities, as evidenced by his publications of international papers, books, his awards and invited lectures. Jim was fascinated in many areas of science and his research included work on printed antenna technology, size reduced antennas, waves in composite materials [1], electromagnetic heating in medical engineering [2], optical systems [3], microwaves and speech processing. Other areas of research include; satcom antennas [4], millimetre wave systems [5], conformal antennas [6], WLAN propagation [7], fractal antennas [8], base station antennas [9], plasma columns [10], guided weapons, stealth radar coatings [11], optical early detection of cancer cells, electromagnetic screening, electromagnetic detection of buried pipes, RF tags for package identification, GSM, UMTS, Bluetooth and metamaterials using nanomaterial research.

\subsection{Text books}

Jim's main area of research was that of antennas and he cowrote the book on Small Antennas [12]. This book covered cutting-edge research into antenna design and practicalities. The book includes; fundamental principles, continuously loaded wire antennas, low profile antennas and the effect of mounting the antenna on realistic objects.

He took advantage and became part of the dramatic increase in technology in the $1980 \mathrm{~s}$, that allowed vast improvements to the miniaturisation and integration of electronic components, to popularise the concept of the microstrip antenna. His book, Microstrip Antenna Theory and Design [13] was the first text book on the subject. Jim had a profound understanding of electromagnetics and this combined with a gifted mathematical ability allowed him to develop the analytical tools used to understand the theory and design implications of the microstrip antenna. The success of this book led to the Handbook of Microstrip Antennas [14]. This book won the 1990 IEE Rayleigh Book Award. These two books are still regularly cited as being the basis of microstrip antenna design.

In 2001, he edited the Mobile Antenna Systems Handbook [15] with his great friend and colleague Professor Fujimoto. This book addresses the main application areas of land, maritime, satellite and aeronautical mobile systems. It covers all types of antennas used in mobile systems and has classified them into generic types so the fundamental principles could be more easily understood.

Dielectric Resonator Antennas [16] was written in 2003. These antennas can be used as small low-profile antennas at low microwave frequencies. This book updated current literature on the subject of DRAs and added new information that had not previously been available.

His latest work was to write a chapter on Mobile Handset Antennas which was published in July 2007 in the $4^{\text {th }}$ Edition of the Antenna Engineering Handbook [17]. This chapter covers the following topics; design issues, helical wire antennas, PIFAs, ceramic chip and resonator antennas, specific absorption rates (SAR), SAR minimisation, GPS, Bluetooth, Satcom and future trends in mobile handset antennas. This work is especially remarkable as despite his severe illness, he still had a passion for antennas and was still at the cutting-edge of technology.

\subsection{Prizes}

In addition to Jim's innovative ideas, his strenuous analytical approach combined with an understanding of how research could be practically implemented won him 9 IEE awards. These include the IERE Heinrick Hertz 1966 prize for his work on p-i-n diodes [18]. He also retained the prize in 1967 with two papers. One about pin diode coaxial attenuators [19] and the other about dielectric rod antennas [20].

Unfortunately, the IET have no official records of former prize winners after 1967 and so the following papers are based on assumption only. The IERE Heinrick Hertz prize was won for a $3^{\text {rd }}$ time in 1973 with a paper on arrays with dielectric slab attachments [21]. In 1978, he won the Blumlein-Browne Willans prize with a paper on microstrip open-circuit terminations [22]. He was awarded the Ambrose Fleming prize in 1985. In $1988 \mathrm{Jim}$ won the Duddell prize for his work on microstrip antennas. He was awarded the Oliver Lodge prize in 1990 and the JJ Thomson prizes in 1991 and 1992. In this three year period, he largely worked on microstrip antennas, but also researched Hilbelt transforms [23], superconducting loop antennas [24], quasi-leaky-wave applicators [25] and dual band planar antennas with interference suppression [26]. Jim was nominated for the highly prestigious 2004 IEE Achievement Award.

\subsection{Invited and review papers}

Jim was considered to be one of the world's leading experts on antennas and was asked to make numerous Presidential and Chairman's presentations. He had a thorough understanding of the entire research area and wrote review papers covering the latest advances.

At ICAP 1989, Jim was invited to make a presentation about the current and future state of antennas. This included 
innovative designs, novelty and creative ideas such as; travelling-wave arrays, apertures, arrays, measurements, and material developments. Jim considered the practical aspects of manufacturing along with some speculation of the future of antennas [27]. He was also suitably experienced to address the enormity of the subject of microwaves and their contribution to the century [28]. This paper reviewed the century's most significant milestones, the state of microwave technology at the time and challenges for the future.

Other invited and review topics covered include medical care using electronics [29], printed antennas [30], microwave integrated circuits [31], personal communications equipment [32] and magnetised ferrites [33].

To honour and celebrate Jim's life and his immense contribution to science, a special session has been dedicated to him at EuCAP 2007. Some of Jim's closest colleagues and great friends presented papers reviewing Jim's career. Ivor Morrow [34] considered Jim's research as a whole. Peter Hall [35] looked at Jim's work on printed antennas. Kyohei Fujimoto [36] reviewed his work on small antennas for mobile systems. Koichi Ito [37] considered Jim's contribution to the field of small antennas for antenna hyperthermia.

\section{Low SAR Ferrite Handset Antenna Design}

Jim had a very good understanding of the power of dielectric and magnetic materials and how their properties could be applied to many different applications. His fascination with them led to the completion of many successful research projects. In addition, he was very interested in the interaction of human tissue with EM radiation, as he realised the importance of the issue both to users and manufacturers. Consequently, he combined the two topics and was concerned with the application of a dielectric-ferrite mix in the design of a multiband, low SAR mobile phone antenna [38]. The benefits from the addition of ferrite compared to dielectric alone were examined using both analytical and experimental methods.

\subsection{Theoretical mathematical model}

Based on the work of Hansen [39] and Stratton [40], and using his strong mathematical background, Jim developed a theoretical mathematical model in order to examine the effect of different material loadings on the size, efficiency, bandwidth and near field of an antenna. The model consisted of a spherical volume of material (of constant product $\varepsilon_{\mathrm{r}} \mu_{\mathrm{r}}$ $=36$ ) excited by an infinitesimally small dipole source. The spherical canonical geometry enabled accurate representation of the fields generated by the antenna and led to the solution of the vector wave equations across the sphere boundary. Consequently, the resonant frequency, radiated fields, $\mathrm{Q}$ and bandwidth could be determined.

Further development of the model and thorough examination of its behaviour, indicated that an equality of permittivity and permeability inside the sphere, provided the best impedance match at the air/material interface and hence maximum radiation, efficiency and bandwidth. Results are shown in Figure 2. In addition, the amplitude of the antenna near fields was reduced for that particular ratio (compared to a purely dielectric or purely magnetic antenna), indicating a low SAR. Having established the theoretical foundations, a computer simulation tool was used to validate the model and examine its application to more realistic antenna shapes and structures.

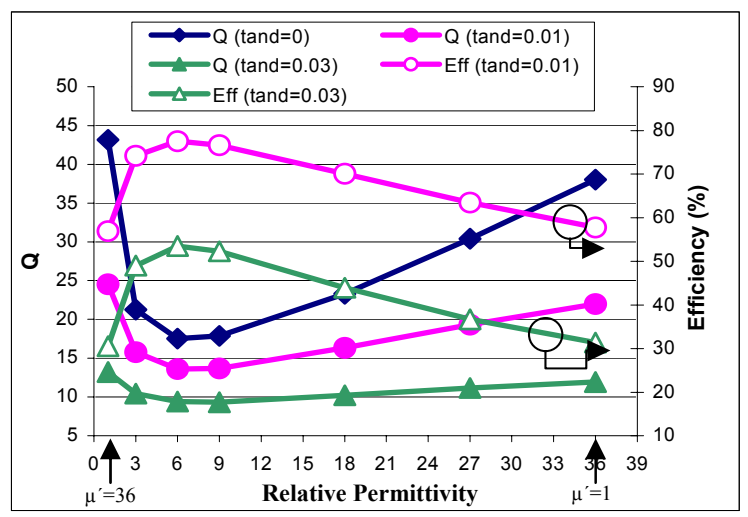

Figure 2. Theoretical Q factor and efficiency performance of spherical material coated resonator.

\subsection{Simulations of material coated resonator antennas}

The validation of the theoretical model was performed by simulating two structures; a sphere and a cube (of constant product $\varepsilon_{\mathrm{r}} \mu_{\mathrm{r}}=36$ ), excited by a finite dipole source. Their variations in efficiency, bandwidth and amplitude of electric fields endorsed the ones predicted from the theoretical model, despite their significant structural differences and the presence of a finite source. Figure 3. shows the efficiency and bandwidth variation with permittivity.

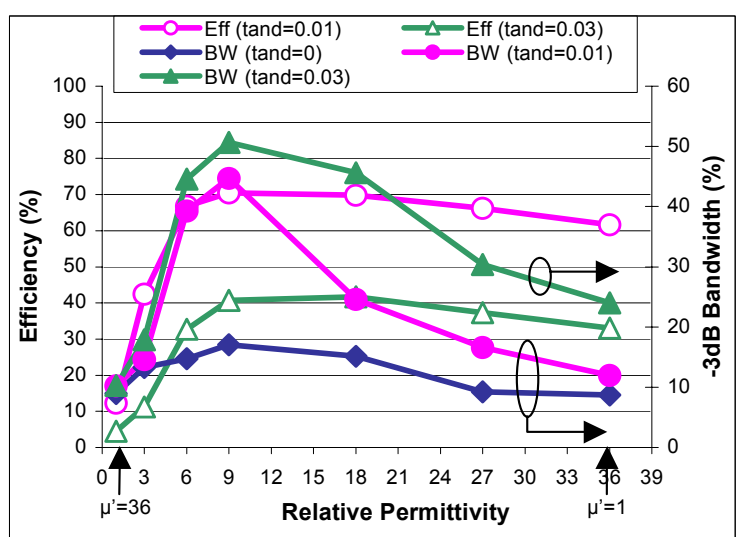

Figure 3. Simulated radiation performance of rectangular material coated antenna with central dipole excitation.

The 30mm cubic resonator was then modelled for a constant resonant frequency of $1800 \mathrm{MHz}$ (varying $\varepsilon_{\mathrm{r}} \mu_{\mathrm{r}}$ product) and was placed against a phantom head in two positions: with its dipole source parallel and then perpendicular to the head. Although, in both cases, the variation of efficiency, 
bandwidth and SAR with permittivity were similar to the ones without the head, the actual values varied significantly. The results highlighted the significance of the dipole orientation in controlling the amount of energy lost inside the head (SAR) and the consequent reduction in efficiency and bandwidth.

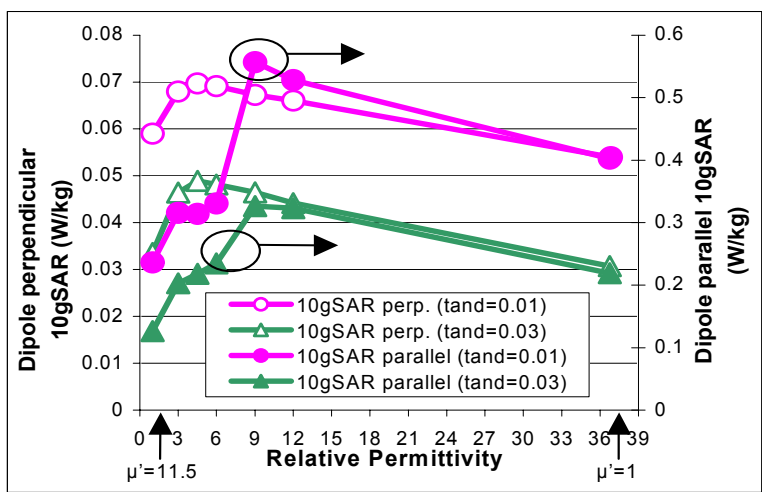

Figure 4. SAR for perpendicular and parallel dipole orientations near a spherical head.

Orientating the dipole perpendicular to the head minimises the radiation lost inside the head and results in increased efficiency and bandwidth. SAR values were reduced by up to $87 \%$. These results are shown in Figure 4.

Hence, it is established that the orientation of the dipole source dominates SAR minimisation while the ferritedielectric material is responsible for maintaining efficiency and bandwidth at the maximum possible levels.

\subsection{Antenna handset design}

Having confirmed the accuracy of the software, the material loaded resonator antenna was integrated into the handset. The antenna comprised of a block of material with $\varepsilon_{\mathrm{r}} \sim \mu_{\mathrm{r}}$ excited by a monopole to ensure a pattern null towards the head, see Figure 5. Using extended developmental simulation work, it was possible to translate the aforementioned attributes into a quad-band design [38], which combined excellent band coverage (GSM 1800, 1900, UMTS, Bluetooth) and simple design with high efficiencies ( $\sim 37 \%)$ and extremely low SAR $(<0.1 \mathrm{~W} / \mathrm{kg})$. An alternative handset antenna design was also simulated with differences to the metallisation used and the position of the source.

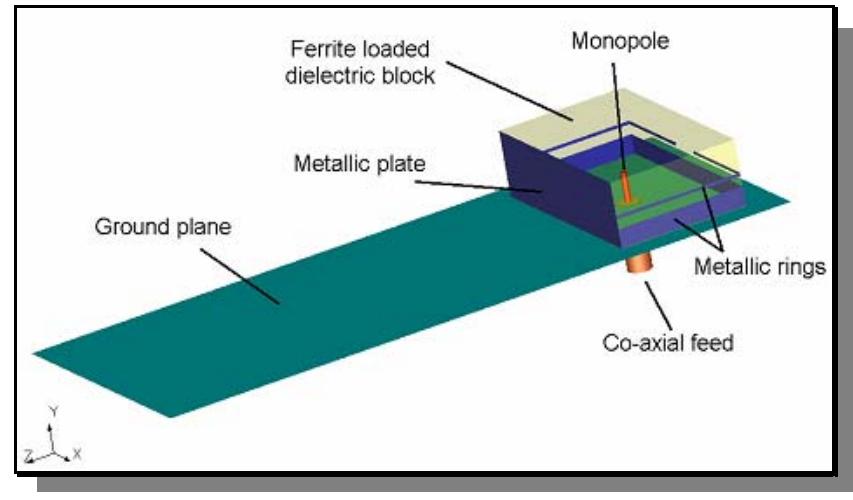

Figure 5. Original Quad-band handset antenna design.
In addition, the detuning effects caused by the presence of the human head and hand were minimal, keeping the antenna efficiencies in the same satisfactory levels. This is unlike other types of antennas (eg. PIFA), which may have higher efficiencies in free space but are greatly affected by their local environment and have a much higher SAR.

The final multi-band antenna design simulated, was a tri-band handset antenna design (GSM 1800, 1900, UMTS), using currently available material with reduced permeability $(\varepsilon r=$ 24.1, $\mu \mathrm{r}=2$ ) [38]. The efficiencies attained were decreased compared to the quad-band designs, however, the results were encouraging considering that this material is used for screening purposes. Also, the radiation patterns indicated low SAR. Table. 1, at the end of this paper, summarises the efficiency and SAR results of the three handset designs.

\subsection{Measurements and comparison to simulations}

Having confirmed the attributes of the material, and identified the appropriate antenna position to obtain optimum performance, the aim was to manufacture and measure such an antenna. Unfortunately, an extensive market research indicated that the existing materials either lacked the required parameters or had excessive losses, which constituted them unsuitable for use in an antenna. It was concluded that the only way to obtain such a material mix would be to manufacture it privately, utilising the properties of hexagonal ferrites. Despite the shortcomings, three different material samples were obtained. The samples didn't possess the necessary properties for a prototype manufacture but were used in order to check the accuracy of the software and indirectly validate the realisation and potential of the material loaded resonator antenna. Three monopole excited, resonator antennas were manufactured. They were simulated and measured and the results obtained successfully validated the software as a suitable tool to predict the material resonator's performance, see Table 2.

\begin{tabular}{|c|c|c|c|c|c|c|}
\cline { 2 - 7 } \multicolumn{1}{c|}{} & \multicolumn{3}{c|}{ Measured } & \multicolumn{3}{c|}{ Simulated } \\
\hline $\begin{array}{c}\text { Sample } \\
\text { no. }\end{array}$ & $\begin{array}{c}f_{0} \\
(\mathrm{GHz})\end{array}$ & $\begin{array}{c}S_{11} \\
(\mathrm{~dB})\end{array}$ & $\begin{array}{c}\eta \\
(\%)\end{array}$ & $\begin{array}{c}f_{0} \\
(\mathrm{GHz})\end{array}$ & $\begin{array}{c}S_{11} \\
(\mathrm{~dB})\end{array}$ & $\begin{array}{c}\eta \\
(\%)\end{array}$ \\
\hline 1 & 1.83 & -14.1 & 15 & 1.78 & -12.0 & 71 \\
\hline 2 & 2.45 & -18.0 & 63 & 2.41 & -12.0 & 67 \\
\hline 3 & 2.43 & -10.6 & 83 & 2.42 & -13.4 & 78 \\
\hline
\end{tabular}

Table 2. Measured and simulated handset designs.

\section{Conclusions}

The advantages of coating an antenna with a dielectric-ferrite material mix, as opposed to dielectric material alone, have been demonstrated both theoretically and experimentally. It is established that apart from higher radiation efficiency and bandwidth, this material coating enables better control over the antenna near fields when placed close to the handset ground plane. Also, the positioning of an axial pattern null towards the head leads to extremely low SAR values. Using developmental simulation work, it was possible to translate 
the aforementioned attributes into two quad-band designs, which combined excellent band coverage with high efficiency and extremely low SAR. Furthermore, it was possible to improve the performance of existing handset antennas and also to explore the antenna's potential with currently available material. It is concluded that the specific development of ferrite material that is more suitable for antenna applications, can lead to the development of the ultimate high efficiency and low-SAR multi-band handset antenna.

Jim was excited by these results and saw great potential in the material loaded mix. Unfortunately, he succumbed to his illness before he could finish his research. There are a lot of issues that he would have liked to deal with, like balancing the antenna, covering the $900 \mathrm{MHz}$ band and realising the effects of the ferrite loaded mix using metamaterials. Having collaborated with such a restless and passionate spirit, Professor Vardaxoglou and his team at Loughborough University will continue to work towards the solutions.

\section{References}

[1] J. R. James, A. J. Race, and L. A. Scott, "Electromagnetic shielding degradation effects in composite material enclosures," Electronic Letters, vol. 35, pp. 209-211, 1999.

[2] J. R. James, C. Hall, and G. Andrasic, "Angled dual compact hyperthermic applicators," IEE Proc.Microw. Antennas Propag., vol. 134, pp. 315-320, 1987.

[3] J. R. James and I. Abd-Eldayem, "Microwave modelling of optical diffraction grating systems," IEE Proc. Optoelectronics, vol. 144, pp. 221-227, 1997.

[4] J. R. James, "Realising satcom antennas," Electronics \& Communication Engineering Journal, vol. 10, pp. 73-82, 1998.

[5] J. R. James and D. J. Harris, "Progress in millimeter wave systems," Radio and Electronic Engineer, vol. 52, pp. 495-496, 1982.

[6] J. R. James, "Conformal antenna synthesis using spherical harmonic wavefunctions," Proceedings of the IEEE, vol. 122, pp. 479-486, 1975.

[7] J. R. James, I. L. Morrow, R. Cushnaghan, and A. S. Fairweather, "Wall surface effects in WLAN propagation environments," Electronic Letters, vol. 39, pp. 267-269, 2003.

[8] G. J. Walker and J. R. James, "Fractal volume antennas," Electronic Letters, vol. 34, pp. 1536$1537,1998$.

[9] X. Zhang, K. M. Luk, C. H. Chan, J. R. James, and C. H. Liang, "Design of a shaped beam cylindrical dipole array for cellular base station," IEE Proc.Microw. Antennas Propag., vol. 147, pp. 295-300, 2000.

[10] I. L. Morrow and J. R. James, "Fundamental limitations on excitation of a surface wave on a plasma column," in Antennas and Propagation
Society International Symposium, 2002. IEEE, 2002, pp. 272-275.

[11] M. B. Amin and J. R. James, "Techniques for utilization of hexagonal ferrites in radar absorbers. Pt .1. Broad-band planar coatings," Radio and Electronic Engineer, vol. 51, pp. 209-218, 1981.

[12] K. Fujimoto, A. Henderson, K. Hirasawa, and J. R. James, Small Antennas Research Studies Press 1986.

[13] J. R. James, P. S. Hall, and C. Wood, Microstrip Antenna Theory and Design: Peter Peregrinus Ltd, 1986.

[14] J. R. James and P. S. Hall, Handbook of Microstrip Antennas: IET, 1989.

[15] K. Fujimoto and J. R. James, Mobile Antenna Systems Handbook: Artech House, 2001.

[16] K. M. Luk, K. W. Leung, and J. R. James, Dielectric Resonator Antennas Research Studies Press 2003.

[17] J. Volakis, Antenna Engineering Handbook, 4th ed: McGraw Hill, 2007.

[18] J. R. James and M. H. Potok, "Wideband coaxial variable attenuators using p-i-n diodes," Radio and Electronic Engineer, vol. 31, pp. 131-144, 1966.

[19] J. R. James and M. H. Potok, "The design of pin diode coaxial attenuators and levellers," Electronic Engineering, vol. 38, pp. 142-146, 1967.

[20] J. R. James, "Theoretical Investigation of cylindrical dielectric rod antennas," IEE Proceedings Science, Measurement \&, vol. 114, pp. 309-319, 1967.

[21] I. N. L. Gallett, R. Graham, J. R. James, M. Scorer, and A. M. Smith, "Gain enhancement of microwave linear arrays with dielectric slab attachments," in 3rd European Microwave Conference, 1973, pp. 1-4.

[22] A. Henderson and J. R. James, "Continuous eigenvalue mode spectrum analysis of microstrip open-circuit terminations," in 8th European Microwave Conference, 1978, pp. 89-93.

[23] J. R. James, "Assessing the accuracy of wideband electrical data using Hilbert transforms," IEE Proc. Microwaves, Antennas and Propagation, vol. 137, pp. 184-188, 1990.

J. R. James, M. White, D. Steel, J. Carney, and M. Gledhill, "System considerations of a superconducting loop antenna," in IEE Colloquium on Electrically Small Antennas, 1990, pp. 7/1-7/4.

[25] G. Andrasic, J. R. James, and J. W. Hand, "Investigation of quasi-leaky-wave applicator using FD-TD computations," in Seventh International Conference on Antennas and Propagation (IEE). ICAP 91 1991, pp. 584-587

[26] A. A. Abdekaziz, A. Henderson, and J. R. James, "Dual band planar antenna with interference suppression," in IEE Colloquium on Multi-Band Antennas, 1992, pp. 1-5.

[27] J. R. James, "What's new in antennas?," IEEE Antennas and Propagation Magazine, vol. 32, pp. 6$18,1990$. 
[28] J. R. James, "Magical microwaves: the exploitation of the century," IEE Proc.-Microw. Antennas Propag., vol. 136, pp. 1-12, 1989.

[29] J. R. James, "Man, medicine and electronics-an awakening frontier," Journal of the Institution of Electronic and Radio Engineers, vol. 55, pp. 1-7, 1985.

[30] J. R. James, "Printed Antennas - New Research Frontiers," in Asia-Pacific Microwave Conference, APMC '92 Adelaide, Australia, 1992, pp. 21-26.

[31] J. R. James, "Advances in microwave integratedcircuits," Radio and Electronic Engineer, vol. 48, pp. 1-2, 1978.

[32] J. R. James, "Mobile antenna systems-highlights of recent developments in personal communication equipment," in Microwave Filters and Antennas for Personal Communication Systems, IEE Colloquium on, London, UK, 1994, pp. 1-4.

[33] A. Henderson, J. R. James, A. Fray, and G. D. Evans, "New ideas for beam scanning using magnetised ferrite," in Electronically Scanned Antennas, IEE Colloquium on, 1988, pp. 1-4.

[34] I. Morrow and J. Dahele, "A historical review on the research work of Professor Jim James," in The Second European Conference on Antennas and Propagation (EuCAP 2007) Edinburgh, UK, 2007.
[35] P. S. Hall, "The contribution of $\mathbf{J} \mathbf{R}$ James to printed antennas," in The Second European Conference on Antennas and Propagation (EuCAP 2007) Edinburgh, UK, 2007.

[36] K. Fujimoto, "Review of small antennas and antennas for mobile systems in memory of Professor J R James," in The Second European Conference on Antennas and Propagation (EuCAP 2007) Edinburgh, UK, 2007.

[37] K. Ito, "Small antenna for antenna hyperthermia " in The Second European Conference on Antennas and Propagation (EuCAP 2007) Edinburgh, UK, 2007.

[38] M. I. Kitra, C. J. Panagamuwa, P. McEvoy, J. C. Vardaxoglou, and J. R. James, "Low SAR ferrite handset antenna design," IEEE Trans Antennas and Propagation, vol. 55, pp. 1155-1164, 2007.

[39] R. C. Hansen, "Fundamental limitations in antennas," Proc. of IEEE, vol. 69, pp. 170-182, 1981.

[40] J. A. Stratton, Electromagnetic Theory. New York: McGraw-Hill Inc, 1941.

\begin{tabular}{|c|c|c|c|}
\hline & $\begin{array}{c}\text { Original Quad-band Handset } \\
\text { Antenna Design }\end{array}$ & $\begin{array}{l}\text { Alternate Quad-band } \\
\text { Handset Antenna Design }\end{array}$ & $\begin{array}{l}\text { Reduced Permeability } \\
\text { Handset Antenna Design }\end{array}$ \\
\hline \multicolumn{4}{|l|}{ GSM 900 band } \\
\hline GSM 1800 band & Achieved & Achieved & Achieved \\
\hline GSM 1900 band & Achieved & Achieved & Achieved \\
\hline UMTS band & Achieved & Achieved & Achieved \\
\hline Blue-tooth band & Achieved & Achieved & \\
\hline $\begin{array}{l}\text { Efficiency (\%) at } \\
\text { respective bands } \\
\text { covered }\end{array}$ & $\begin{array}{l}\text { GSM 1800: } 36.8 \\
\text { GSM 1900: } 36.1 \\
\text { UMTS: } 19.1 \\
\text { Blue-tooth: } 27.5\end{array}$ & $\begin{array}{l}\text { GSM 1800: } 34.8 \\
\text { GSM 1900: } 42.0 \\
\text { UMTS: } 25.4 \\
\text { Blue-tooth: } 25.8\end{array}$ & $\begin{array}{l}\text { GSM 1800: } 21.0 \\
\text { GSM 1900: } 16.0 \\
\text { UMTS: } 12.5\end{array}$ \\
\hline $\begin{array}{c}\text { Efficiency (\%) with } \\
\text { head at respective } \\
\text { bands covered }\end{array}$ & $\begin{array}{l}\text { GSM 1800: } 35.1 \\
\text { GSM 1900: } 32.6 \\
\text { UMTS: } 15.2 \\
\text { Blue-tooth: } 22.3\end{array}$ & $\begin{array}{l}\text { GSM 1800: } 32.0 \\
\text { GSM 1900: } 38.6 \\
\text { UMTS: } 21.8 \\
\text { Blue-tooth: } 20.8\end{array}$ & \\
\hline $\begin{array}{l}\text { Efficiency (\%) with } \\
\text { head and hand at } \\
\text { respective bands } \\
\text { covered }\end{array}$ & $\begin{array}{l}\text { GSM 1800: } 23.3 \\
\text { GSM 1900: } 16.8 \\
\text { UMTS: } 14.8 \\
\text { Blue-tooth: } 13.4\end{array}$ & $\begin{array}{l}\text { GSM 1800: } 20.2 \\
\text { GSM 1900: } 23.5 \\
\text { UMTS: } 16.9 \\
\text { Blue-tooth: } 13.3\end{array}$ & \\
\hline $\begin{array}{l}S A R \log (W / \mathrm{kg}) \text { at } \\
\text { respective bands } \\
\text { covered }\end{array}$ & $\begin{array}{cc}\text { GSM 1800: } & 0.08 \\
\text { GSM 1900: } & 0.11 \\
\text { UMTS: } & 0.06 \\
\text { Blue-tooth: } & 0.0006\end{array}$ & $\begin{array}{ll}\text { GSM 1800: } & 0.04 \\
\text { GSM 1900: } & 0.06 \\
\text { UMTS: } & 0.06 \\
\text { Blue-tooth: } & 0.0001\end{array}$ & \\
\hline
\end{tabular}

Table 1. Summary of simulated multiband antennas. 